\title{
Involvement of RORyt-overexpressing T cells in the development of autoimmune arthritis in mice
}

\author{
Yuya Kondo ${ }^{1}$, Zhaojin Yao ', Masahiro Tahara', Mana lizuka', Masahiro Yokosawa', Shunta Kaneko', Seiji Segawa', \\ Hiroto Tsuboi ${ }^{1}$, Keigyou Yoh', Satoru Takahashi ${ }^{2,3,4,5}$, Isao Matsumoto ${ }^{1}$ and Takayuki Sumida ${ }^{1 *}$
}

\begin{abstract}
Introduction: Differentiation of T helper 17 cells is dependent on the expression of transcription retinoid-related orphan receptor gammat (RORYt). The purpose of our study is to determine the role of RORyt expression in T cells on the development of collagen-induced arthritis (CIA).

Methods: ClA was induced in C57BL/6 and T cell-specific RORyt transgenic (RORyt Tg) mice. At day 10 post-1stimmunization, lymph node (LN) cells were cultured with type II collagen $(\mathrm{CII})$, and the expression levels of various cytokines and transcription factors on $\mathrm{CD} 4^{+} T$ cells were measured. Total cells or $\mathrm{CD} 4^{+}$cells of draining $\mathrm{LN}$ were harvested from each mouse group after Cll-immunization and transferred into C57BL/6 mice, and then CIA was induced in recipient mice. The expression levels of RORyt and other surface antigens, and the production of cytokines were analyzed in forkhead box P3 (Foxp3) ${ }^{+}$regulatory T (Treg) cells. Foxp3 ${ }^{+}$Treg cells were analyzed for suppressive activity against proliferation of effector $\mathrm{CD}^{+} \mathrm{T}$ cells. Interlukin (IL)-10 neutralizing antibody was administrated in the course of CIA.
\end{abstract}

Results: CIA was significantly suppressed in RORyt Tg mice compared with C57BL/6 mice. RORyt expression and IL-17 production were significantly higher in Cll-reactive $\mathrm{CD}^{+} \mathrm{T}$ cells from RORyt Tg mice. Arthritis was significantly attenuated in C57BL/6 mice recipient of cells from RORyt Tg mice. Most of Foxp3 ${ }^{+}$Treg cells expressed RORyt, produced IL-10 but not IL-17, and overexpressed CC chemokine receptor 6 (CCR6) and surface antigens related to the suppressive activity of Foxp3 $^{+}$Treg cells in RORyt Tg mice. In vitro suppression assay demonstrated significant augmentation of the suppressive capacity of Foxp3 ${ }^{+}$Treg cells in RORyt Tg mice. CIA was exacerbated in both C57BL/6 mice and RORyt Tg mice by the treatment of anti-IL-10 antibody.

Conclusion: Our results indicated that RORyt overexpression in T cells protected against the development of CIA. The protective effects were mediated, at least in part, through the anti-inflammatory effects including high production of IL-10 of RORyt ${ }^{+}$Foxp3 $3^{+}$Treg cells.

\section{Introduction}

Rheumatoid arthritis (RA) is a chronic inflammatory disorder characterized by autoimmunity, infiltration of activated inflammatory cells into the joint synovium, synovial hyperplasia, neoangiogenesis, and progressive destruction of the cartilage and bone. This disease affects 1 to $2 \%$ of the population worldwide, most commonly middle-aged women. The etiology of RA is unknown but proinflammatory cytokines seem to play a central role.

\footnotetext{
* Correspondence: tsumida@md.tsukuba.ac.jp

'Department of Internal Medicine, Faculty of Medicine, University of Tuskuba,

1-1-1 Tennodai, Tsukuba City, Ibaraki 305-8575, Japan

Full list of author information is available at the end of the article
}

Thus, correction of any cytokine imbalance can probably control this disease.

$\mathrm{T}$ cells form a large proportion of the inflammatory cells invading the synovial tissue. $\mathrm{CD} 4^{+} \mathrm{T}$ cells are one of the $\mathrm{T}$ cell subsets involved in the RA pathological process. Upon antigenic stimulation and cytokine signaling, naïve $\mathrm{CD} 4^{+} \mathrm{T}$ cells activate and differentiate into various $\mathrm{T}$ helper (Th) subsets [1]. Classically Th cells are divided into Th1 and Th2 subsets according to their cytokine production pattern. Recently, IL-17-producing Th17 cells have been identified and this $\mathrm{T}$ cell population appears to play a critical role in the generation of several types of autoimmune arthritis such as glucose-6-phosphate isomerase (GPI)-induced arthritis [2] and collagen-induced 
arthritis (CIA) [3]. Moreover, blockade of IL-17 after disease onset prevents cartilage and bone destruction, leading to amelioration of the clinical symptoms of the disease in CIA [4]. Another study identified IL-17 receptor signaling as a critical pathway in turning acute synovitis into chronic destructive arthritis [5]. In RA patients, IL-17 is spontaneously produced by the rheumatoid synovium [6], and a high percentage of IL-17-positive $\mathrm{CD} 4^{+} \mathrm{T}$ cells in peripheral blood mononuclear cells have been detected in RA patients compared with healthy control subjects [7]. Therefore, Th17 is considered to be related to the development of RA. Lineage commitment of each Th cell subset from naive $\mathrm{CD} 4^{+} \mathrm{T}$ cells is dependent on the expression of specific transcription factors induced by specific cytokine environment. Each Th cell-specific transcription factor does not only regulate the expression of effector molecules like cytokines and chemokines specific for each Th cell subset, but also negatively regulates the differentiation of other $\mathrm{T}$ cell subsets $[8,9]$.

Differentiation of Th1 and Th2 cells is dependent on the expression of transcription factor T-box transcription factor (T-bet) [10] and GATA binding protein3 (GATA-3) [11], respectively. Similarly, transforming growth factor- $\beta$ (TGF- $\beta$ ) and IL- 6 induce the expression of the transcription factor ROR $\gamma$ t, which upregulates the expression of Th-17-specific molecules, IL-17A, IL-17 F, CC chemokine ligand 20 (CCL20), and chemokine receptor CCR6 in mice [12-14]. Recent studies highlighted the importance of Th cell-specific transcription factors in the development of autoimmune arthritis. For example, in mice models of autoimmune arthritis, GATA-3 expression protects against joint inflammation and destruction by reducing the differentiation of Th17 cells [15]. Furthermore, we reported previously that T-bet expression regulates the development of autoimmune arthritis by suppression of antigen reactive Th17 cells differentiation via interferon (IFN) $\gamma$-independent suppression of ROR $\gamma \mathrm{t}$ expression [16]. In RA patients, $\mathrm{CD}^{+} \mathrm{T}$ cells overexpress IL-17 and RORC (encoding RORyt), compared with healthy control subjects [17]. Thus, more work is needed to determine whether RORYt expression and dominant differentiation of Th17 play a role in the development of autoimmune arthritis.

Recently, Yoh et al. [18] reported that the T cells of ROR $\gamma t$ transgenic (ROR $\gamma \mathrm{t} \mathrm{Tg}$ ) mice under the control of CD2 promoter express high levels of RORyt and exhibit a dominant Th17 differentiation pattern [18]. In the present study, CIA was induced in both RORyt $\mathrm{Tg}$ mice and C57BL/6 mice. The results showed significant protection of RORyt $\mathrm{Tg}$ mice against experimentally induced CIA compared with C57BL/6 mice. Furthermore, although RORyt expression and IL-17 production in type II collagen (CII)-reactive $\mathrm{CD} 4^{+} \mathrm{T}$ cells were significantly higher in RORyt Tg mice, arthritis was significantly attenuated in
C57BL/6 mice recipients of cells from immunized ROR $\gamma \mathrm{t}$ $\mathrm{Tg}$ mice in adoptive transfer of draining lymph node (LN) cells or recipients of $\mathrm{CD} 4^{+}$cells. Foxp $3^{+}$Treg cells overexpressed ROR $\gamma$ t and CCR6, produced IL-10 but not IL-17, and preferentially infiltrated into the joints of RORyt $\mathrm{Tg}$ mice, compared with C57BL/6 mice, after the induction of CIA. In vitro suppression assay demonstrated that the suppressive activity of Foxp $3^{+}$Treg cells was significantly augmented in RORyt Tg mice compared with C57BL/6 mice. CIA was significantly exacerbated in RORyt $\mathrm{Tg}$ mice by the administration of neutralizing antibody of IL-10. Our results suggest that the inhibition of arthritis in RORyt $\mathrm{Tg}$ mice was mediated by suppressor cell subsets, including IL-10 producing CCR6 ${ }^{+}$RORyt ${ }^{+}$Foxp $3^{+}$Treg cells.

\section{Methods}

Mice

Age- and sex-matched C57BL/6 mice and C57BL/6 CD2RORyt Tg mice (age 6 to 10 weeks) were used in our experiments. RORyt Tg mice were prepared by backcrossing mice on the C57BL/6 background. For the isolation of Treg cells, RORyt Tg and C57BL/6 mice were crossed with knockin mice with Foxp3-IRES-green fluorescent protein (GFP) (C57BL/6-Foxp3 ${ }^{\mathrm{GFP}}$ and RORyt Tg-Foxp3 ${ }^{\mathrm{GFP}}$ mice) provided by $\mathrm{B}$ Malissen (Université de la Méditerranée, Marseille, France). All mice were maintained under specific pathogen-free conditions. All experiments described in this report were performed according to the Guide for the Care and Use of Laboratory Animals at the University of Tsukuba, and were approved by the Animal Ethics Review Committee of the University of Tsukuba.

\section{Induction of collagen-induced arthritis}

Native chicken CII was obtained from Sigma-Aldrich (St Louis, MO, USA). CII was dissolved in $0.01 \mathrm{M}$ acetic acid and emulsified in complete Freund's adjuvant (CFA). CFA was prepared by mixing $5 \mathrm{mg}$ heat-killed Mycobacterium tuberculosis (H37Ra; Difco Laboratories, Detroit, MI, USA) and $1 \mathrm{~mL}$ incomplete Freund's adjuvant (Sigma-Aldrich). Mice were immunized intradermally at the base of the tail with $200 \mu \mathrm{g}$ CII in CFA on days 0 and 21. Arthritis was evaluated visually, and changes in each paw were scored on a scale of 0 to 3 as follows; $0=$ normal, $1=$ slight swelling and/or erythema, $2=$ pronounced swelling, $3=$ ankylosis. The score was summed for each limb (maximum score $=12$ ). For histological assessment, mice were sacrificed at day 42 post first CII immunization, and both hind limbs were removed. After fixation and decalcification, the joints were cut into sections and stained with hematoxylin and eosin. Quantification of histological changes was carried out by two independent and blinded observers, and a histological score was assigned to each joint based on the degree of inflammation and erosion, as described previously $[16,19]$. In the experiment of IL-10 
neutralization in the course of CIA, $100 \mu \mathrm{g}$ of anti-IL-10 antibody (JES5-16E3; BioLegend, San Diego, CA, USA) or isotype control antibody (RTK4530; BioLegend) was administrated intraperitoneally every 2 days from day 22 to 30 post first CII immunization.

\section{Cell isolation}

Inguinal lymph nodes were collected as draining LNs, and used for the experiments. $\mathrm{CD} 4^{+}$cells in draining LNs and spleen were isolated by positive selection using a magneticactivated cell sorting (MACS) system with anti-CD4 mAb (Miltenyi Biotec, Bergisch Gladbach, Germany). CXC chemokine receptor $5^{+}$(CXCR5) follicular helper $\mathrm{T}$ (Tfh) cells were isolated with Moflo cell sorter (DakoCytomation, Glostrup, Denmark) from MACS-isolated $\mathrm{CD}^{+} \mathrm{T}$ cells. For the isolation of Foxp $3^{+}$Treg cells and Foxp $3^{-}$non-Treg cells, $\mathrm{CD} 4^{+} \mathrm{GFP}^{+}$and $\mathrm{CD} 4^{+} \mathrm{GFP}^{-}$cells were further purified using a Moflo cell sorter from MACS-isolated $\mathrm{CD}^{+}{ }^{+} \mathrm{T}$ cells in C57BL/6-Foxp3 ${ }^{\mathrm{GFP}}$ and RORyt Tg-Foxp3 ${ }^{\mathrm{GFP}}$ mice. The isolated cells were used for the experiment of adoptive cell transfer and quantitative reverse transcriptase-polymerase chain reaction (RT-PCR) (see below).

\section{Adoptive cell transfer experiment}

All cells of draining $\mathrm{LN}$ and $\mathrm{CD} 4^{+}$cells were harvested from C57BL/6 mice and RORyt Tg mice at day 10 post first $\mathrm{CII}$ immunization. Cells were resuspended in PBS, and $1 \times$ $10^{7}$ cells from the draining LNs or $2 \times 10^{6}$ of $\mathrm{CD}^{+}$cells were injected intravenously into C57BL/6 mice at day 10 post first CII immunization. Recipient mice were immunized with CII in CFA intradermally on day 11 after the cell transfer. Arthritis was evaluated visually as described above.

\section{Quantitative RT-PCR}

Total RNA was prepared from Tfh cells isolated from draining LNs on day 10 post first CII immunization with RNeasy Plus Micro (QIAGEN, Venlo, Netherlands) according to the instructions provided by the manufacturer. cDNA was obtained by reverse transcription with a commercially available kit (TaKaRa Bio, Otsu, Japan). A TaqMan Assayon-Demand gene expression product was used for realtime PCR (Applied Biosystems, Foster City, CA, USA). The expression levels of IL21and Bcl6 were normalized relative to the expression of GAPDH. Analysis was performed with ABI Prism 7500 apparatus (Applied Biosystems).

\section{Cell culture}

Draining LN cells were harvested from each mouse at day 10 post first CII immunization. Single cell suspension was prepared, and LN cells $\left(4 \times 10^{5}\right.$ cells/well on a 96-well round-bottom plate) were cultured in Roswell Park Memorial Institute (RPMI) 1640 medium (SigmaAldrich) containing 10\% FBS, 100 units $/ \mathrm{mL}$ of penicillin, $100 \mu \mathrm{g} / \mathrm{mL}$ of streptomycin, and $50 \mu \mathrm{M} 2$-mercaptoethanol.
The LN cells were cultured in the presence of $100 \mu \mathrm{g} / \mathrm{mL}$ denatured chicken CII for $72 \mathrm{~h}$ and analyzed for CIIreactive cytokine production. Furthermore, $\mathrm{CD}^{+} \mathrm{GFP}^{+}$ were stimulated with Dynabeads Mouse T-activator CD3/ CD28 (Invitrogen, Carlsbad, CA, USA) (1 bead/cell) in round-bottomed 96-well dishes for $96 \mathrm{~h}$ and the amount of IL-10 produced by Foxp3 ${ }^{+}$Treg cells was measured.

\section{Chemotaxis assay}

Cell migration was evaluated using a 24-well, 3- $\mu \mathrm{m}$ pore-size Transwell system (Corning, Lowell, MA, USA). Briefly, $5 \times 10^{5}$ or $2.5 \times 10^{5}$ of $\mathrm{CD}_{4}^{+}$cells isolated from draining LN cells were placed on the top of the Transwell, while CCL20 was added to the bottom of the Transwell system with or without $10 \mu \mathrm{g} / \mathrm{mL}$ of anti-IL-10 mAb or isotype control antibody. After $4 \mathrm{~h}$ of incubation at $37^{\circ} \mathrm{C}$, the number of cells that migrated into the lower well was counted by flow cytometry. Foxp3 expression in the isolated $\mathrm{CD}^{+}$cells was also analyzed by flow cytometry before and after the migration.

\section{Flow cytometry}

For flow cytometry, the cell surface was stained with the following antibodies specific for mouse proteins: anti-CD4 (RM4-5 or GK1.5), anti-CD3 (145-2C11), anti-programmed cell death-1 (29 F.1A12), anti-inducible T-cell co-stimulator (ICOS) (C398.4A), anti-CC chemokine receptor 6 (CCR6) (29-2 L17), anti-cytotoxic T-lymphocyte-associated protein 4 (CTLA4) (UC10-4B9), anti-glucocorticoid-induced tumor necrosis factor receptor (GITR) (DTA-1; all from BioLegend) and anti-CXCR5 CXCR5 (2G8; BD PharMingen, San Diego, CA, USA). For intracellular cytokine staining, cells were cultured with or without $\mathrm{CII}$ for $72 \mathrm{~h}$, and GolgiStop (BD PharMingen) was added during the last $4 \mathrm{~h}$ of each culture. The cell surface was stained and then permeabilized with Cytofix/Cytoperm solution (BD PharMingen). This was followed by intracellular cytokine staining with anti-IL-17A (TC11-18H10; BD PharMingen), anti-IFNY (XMG1.2; BioLegend), and anti-IL-10 antibodies (JES5-16ES; BioLegend). Mouse Regulatory T Cell Staining Kit (eBioscience, San Diego, CA, USA) was used to stain the transcription factors with anti-Foxp3 (MF-14; Biolegend), anti-T-bet (eBio4B10) and anti-RORyt antibodies (AFKJS-9; both from eBioscience). Annexin V (BioLegend) and propidium iodide (PI) (BioLegend) are used for the detection of apoptotic cells. Data were acquired on a FACSCalibur flow cytometer (Becton Dickinson, Mountain View, CA, USA), and analyzed with FlowJo software (Tree Star, Ashland, OR, USA).

\section{Analysis of cytokine profiles}

The supernatants were collected after the cells were cultured with or without CII for $72 \mathrm{~h}$ and the levels of IL-17, IFN $\gamma$, and IL-10 were analyzed by ELISA using the Quantikine ELISA kit (R\&D Systems, Minneapolis, MN, USA). 


\section{Measurement of collagen-specific IgG titers}

Fifty-six days post first CII immunization, serum was collected, then diluted 1:4,000 in blocking solution containing $1 \%$ bovine serum albumin (Wako Pure Chemical Industries, Osaka, Japan) in PBS. Collagen-specific total IgG, IgG1, IgG2a, IgG2b, and IgG3 titers were measured by coated $10 \mu \mathrm{g} / \mathrm{mL}$ of CII in PBS on 96-well plates (Nunc Maxisorp; Nalge Nunc International, Roskilde, Denmark). The optical density was read at $450 \mathrm{~nm}$ using a microplate reader.

\section{In vitro suppression assay and Treg culture}

Responder cells $\left(\mathrm{CD} 4^{+} \mathrm{CD} 25^{-} \mathrm{GFP}^{-}\right)$were labelled with $5 \mu \mathrm{M}$ carboxyfluorescein diacetate succinimidyl ester (CFSE, Invitrogen), then cultured with or without unlabeled Treg cells $\left(\mathrm{CD}^{+} \mathrm{GFP}^{+}\right)$at the indicated ratio for $96 \mathrm{~h}$ in the presence of Dynabeads Mouse T-activator CD3/CD28 (1 bead/cell) in round-bottomed 96-well dishes. The proliferation inhibition rate on the responder was calculated as: (1-(CFSE percentage Treg plus responder cells co-culture / responder cells alone)) X 100\%.

\section{Statistical analysis}

Data are expressed at mean \pm standard error of the mean (SEM). Differences between groups were examined for statistical significance using Student's $t$-test. $P$-values $<0.05$ were considered significant.

\section{Results}

\section{Suppression of CIA in RORyt Tg mice}

To evaluate the effects of T cell-specific RORyt expression on the development of arthritis, we compared the severity of CIA in RORyt Tg mice and C57BL/6 mice. The incidence of arthritis in RORyt Tg mice was markedly suppressed compared with C57BL/6 mice (Figure 1A). Similarly, the arthritis score was also markedly lower in RORyt Tg than C57BL/6 mice (Figure 1B). Histological analysis of arthritic joints showed widespread infiltration of inflammatory cells and synovial hypertrophy throughout joint tissues of C57BL/6 mice, but not those of RORyt Tg mice (Figure 1C). Furthermore, analysis of joint inflammation and erosion scores showed significant suppression of inflammation and destruction in RORyt Tg mice compared
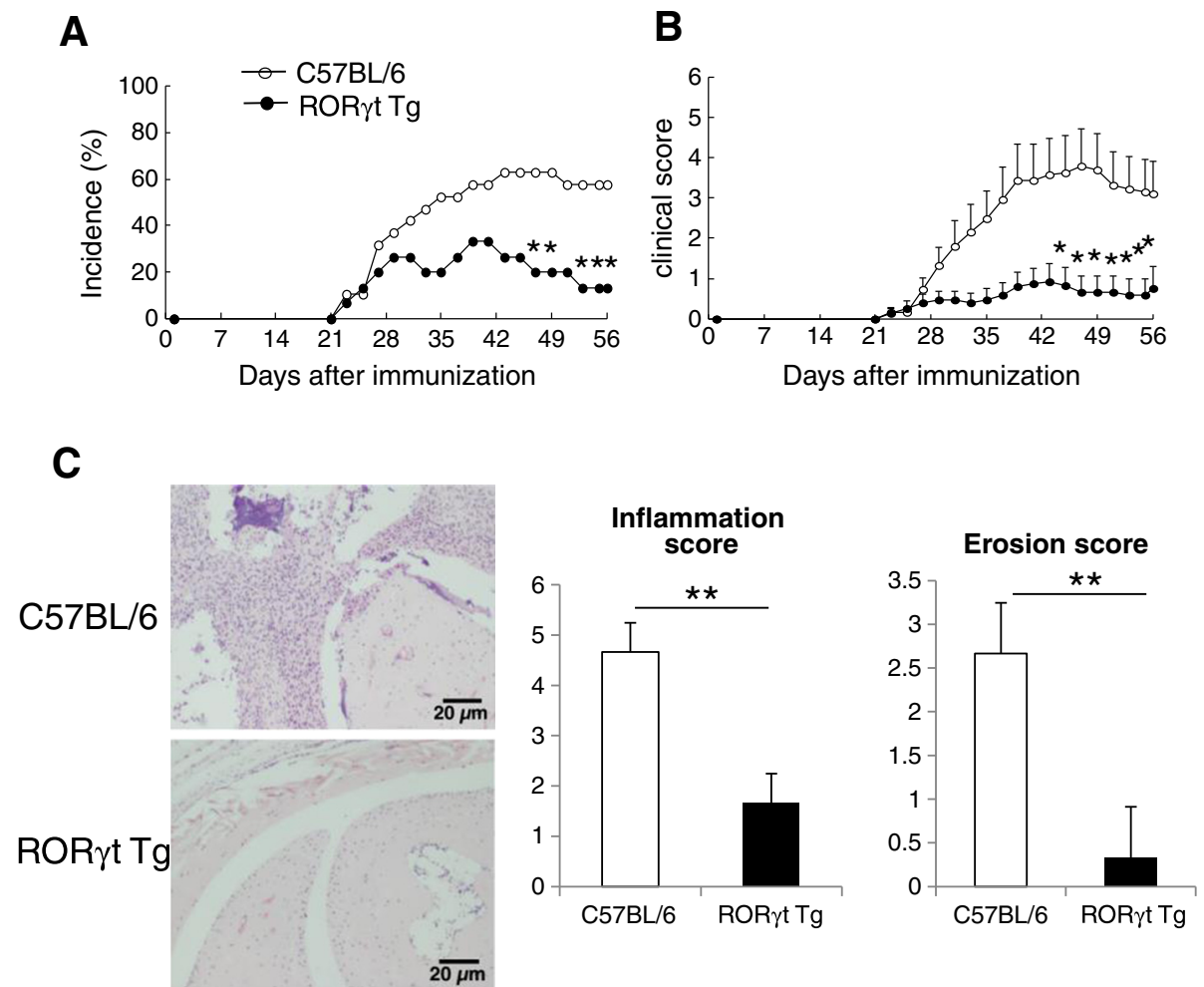

Figure 1 Significant suppression of collagen-induced arthritis (CIA) in RORyt Tg mice. Wild-type (WT) C57BL/6 mice $(n=19)$ and RORyt Tg mice $(n=15)$ were immunized intradermally with chicken type II collagen (CII) emulsified with complete Freund's adjuvant (CFA) on days 0 and 21. (A) Incidence of arthritis. (B) Severity of CIA. Data obtained from three independent experiments. (C) At day 42 post first Cll immunization, joint pathology was evaluated on decalcified hematoxylin and eosin-stained sections. Inflammation and bone erosion scores were assessed in both groups. Data are mean \pm standard error of the mean. ${ }^{*} P<0.05$, ${ }^{*} P<0.01$, versus C57BL/ 6 mice, Student's $t$-test. 


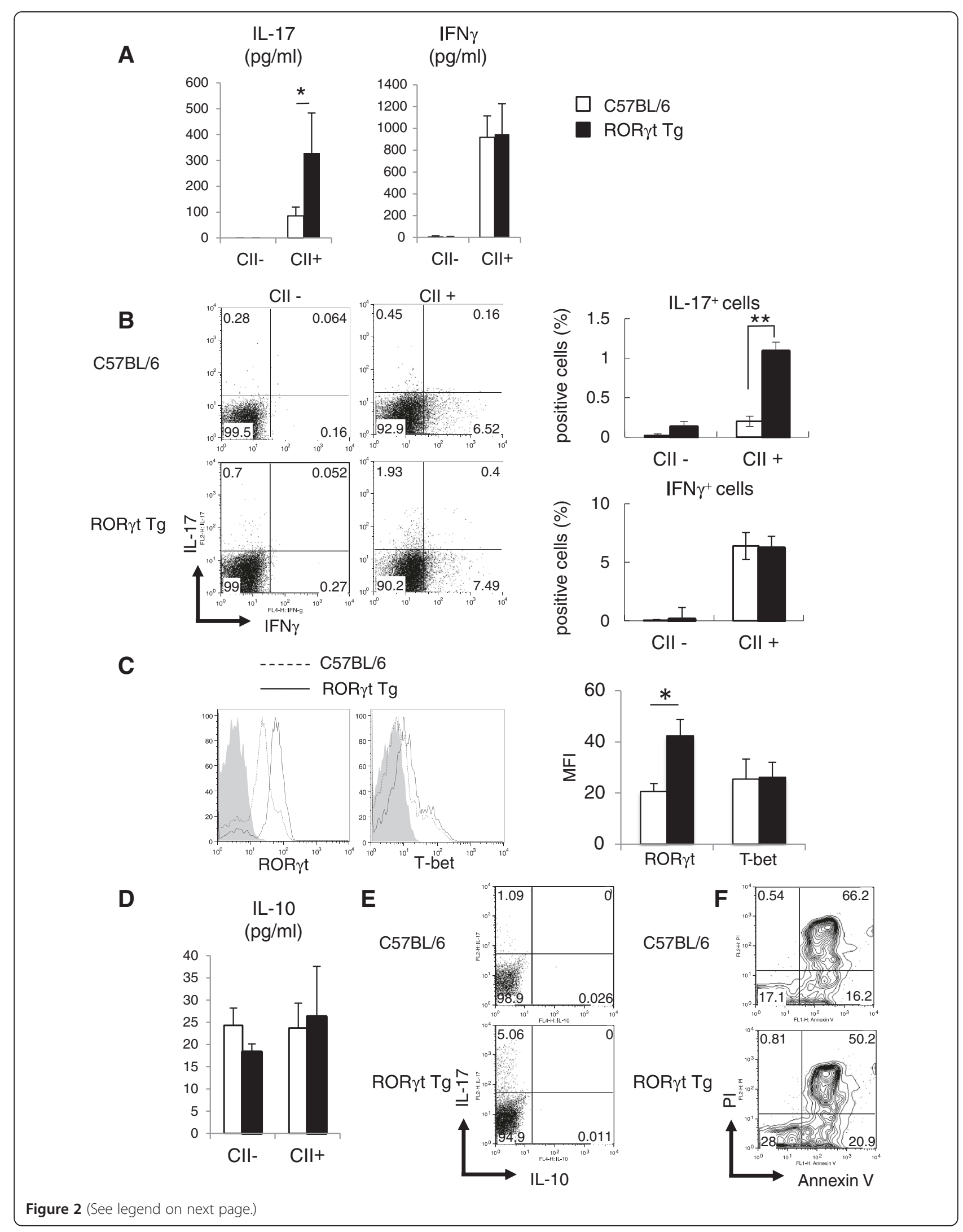


(See figure on previous page.)

Figure 2 Cytokine production and transcription factor expression in antigen reactive CD4 ${ }^{+}$T cells. At day 10 days post first type II collagen (CII) immunization, draining lymph node (LN) cells from C57BL/6 mice ( $\mathrm{n}=3$ or 4 ) and RORyt Tg mice ( $\mathrm{n}=3$ or 4$)$ were cultured with or without $100 \mathrm{\mu g} / \mathrm{mL}$ of denatured Cll for $72 \mathrm{~h}$. (A) IL-17 and IFNy levels in supernatants measured by ELISA. (B) Cells were analyzed by staining for intracellular IL-17 and IFNy. Data represent gated $\mathrm{CD}^{+}$and CD4 ${ }^{+}$. Bar graphs show percentages of cytokine-positive cells. (C) The expression levels of RORyt and T-bet were evaluated by intracellular staining. Data represent gated $C D 3^{+}$and $C D 4^{+}$. In the histograms, the gray shaded area represents data for the isotype control. Bar graphs show mean fluorescence intensity (MFI) of T-bet and RORyt Tg. (D) IL-10 levels in supernatants measured by ELISA. (E, F) Cells were analyzed by staining for intracellular IL-17 and IL-10 (E), and propium iodide (PI) and Annexin V (F). Data represent gated CD3 ${ }^{+}$and $C D 4^{+}$. Data are representative of two independent experiments with similar results, and are mean \pm standard error of the mean. ${ }^{*} P<0.05$, ${ }^{* *} P<0.01$, versus C57BL/6 mice, Student's t-test.

with C57BL/6 mice (Figure 1C). These results indicate that RORyt Tg-expressing T cells suppressed the development of CIA.

\section{Overexpression of RORyt modulates differentiation of Cll-reactive $\mathrm{CD}^{+} \mathrm{T}$ cells}

To determine the effects of RORyt overexpression on CIIreactive cytokine production, we analyzed draining LN cells harvested at day 10 post first CII immunization. These cells were stimulated with $\mathrm{CII}$ in vitro before measurement of cytokine levels in supernatants by ELISA. The level of IL17 was significantly higher in RORyt Tg mice than in C57BL/6 mice, whereas that of IFN $\gamma$ was comparable in the two groups (Figure 2A). Fluorescence-activated cell sorting (FACS) analysis of cytokine expression on $\mathrm{CD}^{+} \mathrm{T}$ cells also showed no significant difference in IFN $\gamma$ production from CII-reactive $\mathrm{CD}^{+} \mathrm{T}$ cells between the two groups of mice (Figure 2B). The same analysis showed a significantly higher IL-17 production by CII-reactive CD $4^{+}$ $\mathrm{T}$ cells of ROR $\gamma \mathrm{t} \mathrm{Tg}$ mice compared with $\mathrm{C} 57 \mathrm{BL} / 6$ mice (Figure 2B). We measured the expression of transcription factors critical for differentiation of each $\mathrm{CD} 4^{+} \mathrm{T}$ cells subset. The mean fluorescence intensity (MFI) of RORyt in CII-reactive CD4 ${ }^{+} \mathrm{T}$ cells was significantly higher in ROR $\gamma \mathrm{t}$ $\mathrm{Tg}$ mice than C57BL/6 mice (Figure 2C), but there was no difference in T-bet expression between C57BL/6 and RORyt Tg mice (Figure 2C). We also measured IL-10 production by CII-reactive CD4 ${ }^{+} \mathrm{T}$ cells by ELISA and FACS. There was no significant difference in the level of IL-10 between the two groups of mice (Figure 2D), and IL-10 production by CII-reactive $\mathrm{CD}^{+} \mathrm{T}$ cells was almost undetectable with FACS analysis in both mice (Figure 2E). Finally, we examined whether overexpression of RORyt in T cells increases apoptosis in these cells. FACS analysis of apoptotic cells stained with PI and annexin V showed that there was no significant difference between the two groups of mice in the percentage of apoptotic cells in $\mathrm{CD}^{+}{ }^{+} \mathrm{T}$ cells cultured with $\mathrm{CII}$ in vitro (Figure $2 \mathrm{~F}$ ). These results indicate that overexpression of ROR $\gamma \mathrm{t}$ induced higher IL-17 production from CII-reactive $\mathrm{CD}_{4}^{+} \mathrm{T}$ cells, but had no effect on Th1 differentiation and CII-reactive cytokine production other than IL-17,

\section{Suppression of anti-Cll antibody formation}

We examined CII-specific IgG production in ROR $\gamma \mathrm{t} \mathrm{Tg}$ mice, because CII-specific IgG level is known to correlate with the development of CIA [20]. Sera were collected at day 56 post first CII immunization, and the levels of CII-specific total IgG, IgG1, IgG2a, IgG2b, and IgG3 were measured by ELISA. Serum CII-specific total IgG was significantly lower in RORyt $\mathrm{Tg}$ mice than C57BL/6 mice $(P<0.05$, Figure $3 \mathrm{~A})$, but there was no significant difference in CII-specific IgG1, IgG2a, IgG2b and IgG3 (Figure 3B).

The next experiment examined whether the expression of ROR $y$ t affected the differentiation and function of $\mathrm{T}$ follicular helper (Tfh) cells. For this purpose, we measured the expression of CXCR5, programmed death-1 (PD-1), and inducible T-cell co-stimulator (ICOS), a marker of Tfh cells, by FACS analysis of $\mathrm{CD}^{+}$cells in draining LNs, the expression of B cell lymphoma 6 (Bcl-6), a master transcription factor of Tfh cell differentiation, and the expression of IL-21 in Tfh cells. The expression of Bcl-6 and IL-21 were conducted at day 10 post first CII immunization by real-time PCR using $\mathrm{CXCR} 5^{+} \mathrm{CD} 4^{+}$Tfh cells from draining LNs sorted by FACS. The FACS analysis showed significantly higher expression of CXCR5 in CD4 ${ }^{+}$ $\mathrm{T}$ cells in RORyt Tg mice than C57BL/6 mice (Figure 3C). In addition, $\mathrm{ICOS}^{+} \mathrm{PD}-1^{+}$cells in $\mathrm{CXCR} 5^{+} \mathrm{CD} 4^{+}$cells was significantly increased in ROR $\gamma \mathrm{t} \mathrm{Tg}$ mice compared with C57BL/6 mice (Figure 3D). On the other hand, the expression level of Bcl-6 was significantly lower on $\mathrm{CXCR} 5^{+} \mathrm{CD} 4^{+}$ Tfh cells of ROR $\gamma \mathrm{t} \mathrm{Tg}$ mice than that of C57BL/6 mice, and the expression levels of IL- 21 on $\mathrm{CXCR} 5^{+} \mathrm{CD} 4^{+} \mathrm{Tfh}$ cells also tended to be reduced in RORyt $\mathrm{Tg}$ compared with C57BL/6 mice (Figure 3E), suggesting the possibility that the differentiation and the function of Tfh cells is suppressed in RORyt Tg mice. These results indicate that suppression of CIA might be related to decreased anti-CII antibody formation caused by the dysfunction of Tfh cells in RORyt Tg mice.

\section{Transfer of T cells from RORyt Tg mice suppresses CIA in immunized C57BL/6 mice}

To determine whether the suppressor cells regulate the development of arthritis in RORyt Tg mice, cells from draining 


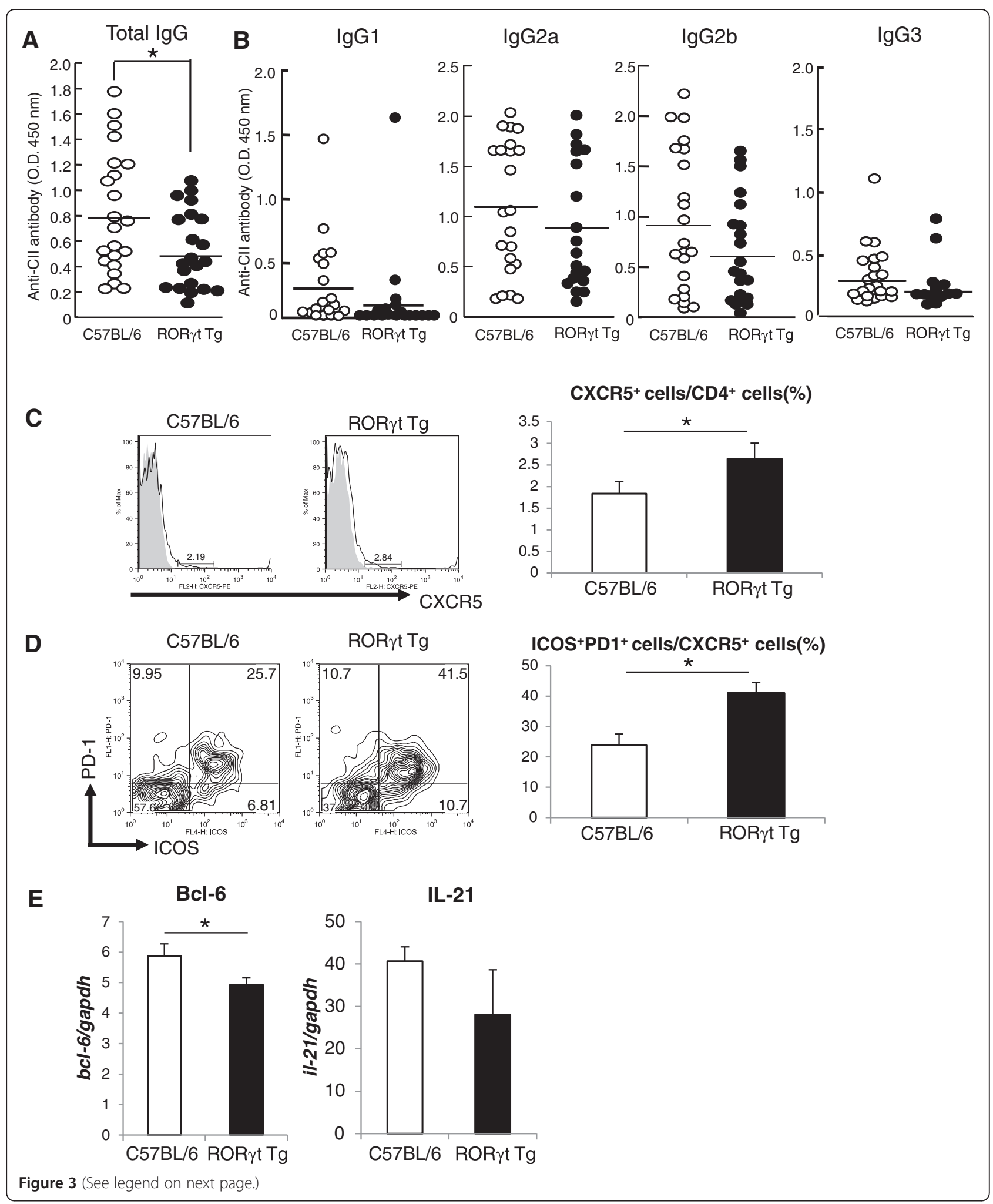


(See figure on previous page.)

Figure 3 Suppression of autoantibody formation. (A, B) At day 56 post first type II collagen (Cll) immunization, serum samples were collected from C57BL/6 mice $(n=22)$ and RORyt Tg mice $(n=21)$ for measurement of Cll-specific total lgG levels $(\mathbf{A})$, and CIl-specific lgG1, IgG2a, IgG2b, and IgG3 (B) by ELISA. Horizontal lines represent the mean values. (C, D) At day 10 post first Cll immunization, the expression of CXCR5 (C) and the expression of inducible T-cell co-stimulator (ICOS) and programmed cell death-1 (PD-1) (D) in draining lymph nodes (LNs) were analyzed by fluorescence-activated cell sorting (FACS). Data represent gated $C D 4^{+}$(C) and CXCR5 ${ }^{+} C D 4^{+}$cells (D). Bar graphs show percentages of CXCR5 ${ }^{+}$ cells (C) and ICOS ${ }^{+}$PD $-1^{+}$cells (D). (E) CDNA was obtained from sorted CXCR5 ${ }^{+}$CD4 $4^{+}$T cells isolated from draining LNs on day 10 post first CII immunization, and expression levels of BCl-6 and IL-21 were analyzed by real-time PCR. Data are representative of two independent experiments with similar results, and represent the mean \pm standard error of the mean. ${ }^{*} P<0.05$, versus C57BL/6 mice, Student's $t$-test.

LN from immunized C57BL/6 mice or ROR $\gamma \mathrm{t}$ Tg mice were adoptively transferred into immunized C57BL/6 mice, followed by induction of CIA. Interestingly, arthritis was significantly suppressed in mice recipient of cells from ROR $\gamma \mathrm{t}$ $\mathrm{Tg}$ mice but not those from C57BL/6 mice (Figure 4A). To identify the effectual cells, only $\mathrm{CD}^{+}$cells isolated from draining LN of C57BL/6 mice or RORyt Tg mice were adoptively transferred into immunized $\mathrm{C} 57 \mathrm{BL} / 6$ mice. Arthritis was also suppressed in mice recipient of $\mathrm{CD} 4^{+}$cells isolated from RORyt $\mathrm{Tg}$ mice only, but not from $\mathrm{C} 57 \mathrm{BL} / 6$ mice (Figure 4B). These results suggest that $\mathrm{CD} 4^{+} \mathrm{T}$ cells inhibit the development of autoimmune arthritis in RORyt Tg mice.

\section{RORyt overexpression augments the suppressive function of Foxp $3^{+}$Treg cells}

Foxp3-expressing $\mathrm{CD}^{+}{ }^{+} \mathrm{T}$ cells are known to suppress $\mathrm{T}$ cell-mediated immune reaction [21]. In the next series of experiments, the expression of Foxp3 in $\mathrm{CD}^{+}{ }^{+} \mathrm{T}$ cells was investigated by intracellular staining using $\mathrm{LN}$ cells harvested at day 10 post first CII immunization. Although there was no significant difference in Foxp3 expression in CD4 $4^{+} \mathrm{T}$ cells between RORyt Tg mice and C57BL/6 mice, higher expression of RORyt in Foxp3 $3^{+}$Treg cells was noted in RORyt Tg mice compared with C57BL/6 mice (Figure 5A, B).

To evaluate whether RORyt ${ }^{+}$Foxp $^{+}$Treg cells of RORyt Tg mice retain their stability and suppressive capacity, we analyzed the production of IL-17 and the expression of molecules known to be related to Foxp $3^{+}$Treg cell function. The FACS analysis of $\mathrm{CD}^{+}{ }^{+} \mathrm{T}$ cells stimulated with CII in vitro showed IL-17 was produced only by Foxp3 ${ }^{-}$non-Treg cells in ROR $\gamma \mathrm{t}$ Tg mice (Figure 5C). The expression of CD25 (Figure 5D), which is associated with the stability of Foxp3 expression [22], was not significantly different between C57BL/6 and ROR $\gamma \mathrm{t}$ Tg mice. Although there was no difference in the expression of CTLA4, that of the co-inhibitory molecule, glucocorticoid-induced tumor necrosis factor receptor (GITR) was significantly higher in RORyt Tg than C57BL/6 mice (Figure 5E), suggesting that stability and suppressive capacity was not affected with overexpression of ROR $\gamma$ t in Foxp $3^{+}$Treg cells.

To provide an answer to the question of whether Foxp3 + cells can suppress effector cell proliferation in vitro, we compared the ability of isolated $\mathrm{CD}^{+} \mathrm{GFP}^{+}$cells from C57BL/6-Foxp $3^{\text {GFP }}$ and RORyt-Foxp3 ${ }^{\text {GFP }}$ reporter mice to inhibit the proliferation of $\mathrm{CD} 4^{+} \mathrm{CD} 25^{-} \mathrm{GFP}^{-}$cells from C57BL/6-Foxp3 ${ }^{\mathrm{GFP}}$ mice in vitro. Interestingly, the suppressive capacity of $\mathrm{CD}^{+} \mathrm{GFP}^{+}$Treg cells was significantly enhanced in RORyt Tg Foxp3 ${ }^{\text {GFP }}$ mice compared with C57BL/6-Foxp3 ${ }^{\text {GFP }}$ reporter mice (Figure 5F), and $\mathrm{CD}^{+} \mathrm{GFP}^{+}$cells isolated from ROR $\gamma \mathrm{t}$ Tg Foxp $3^{\mathrm{GFP}}$ mice produced a larger amount of IL-10 than C57BL/6Foxp3 ${ }^{\mathrm{GFP}}$ mice (Figure 5G). These results indicate that overexpression of ROR $\gamma$ t seems to enhance the suppressive function of Foxp $3^{+}$Treg cells in RORyt Tg mice.
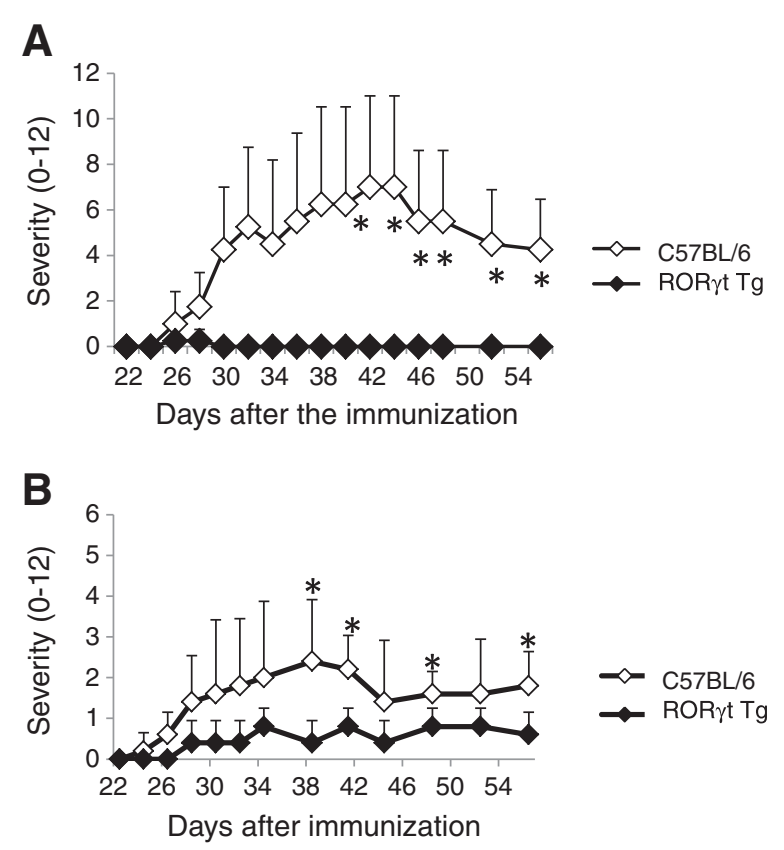

Figure 4 Suppression of collagen-induced arthritis (CIA) in mice after adoptive transfer of cells from RORyt Tg mice. (A) Severity scores of arthritis. Total draining lymph-node cells were harvested from C57BL/6 mice and RORyt Tg mice at day 10 post first type II collagen (CII) immunization, and $1 \times 10^{7}$ cells were injected into C57BL/6 mice intravenously at day 10 post first Cll immunization. Recipient mice were also immunized with Cll in complete Freund's adjuvant (CFA) intradermally on day 11 after the cell transfer. (B) CD4 ${ }^{+}$cells were isolated from draining lymph nodes of C57BL/6 mice and RORyt Tg mice at day 10 post first Cll immunization, and $2 \times 10^{6}$ cells were injected intravenously into C57BL/6 mice at day 10 post first Cll immunization, followed by induction of CIA using the method described for $\mathbf{A}$. Data are representative of two independent experiments with similar results, and are mean \pm standard error of the mean. ${ }^{*} P<0.05$, Student's $t$-test. 


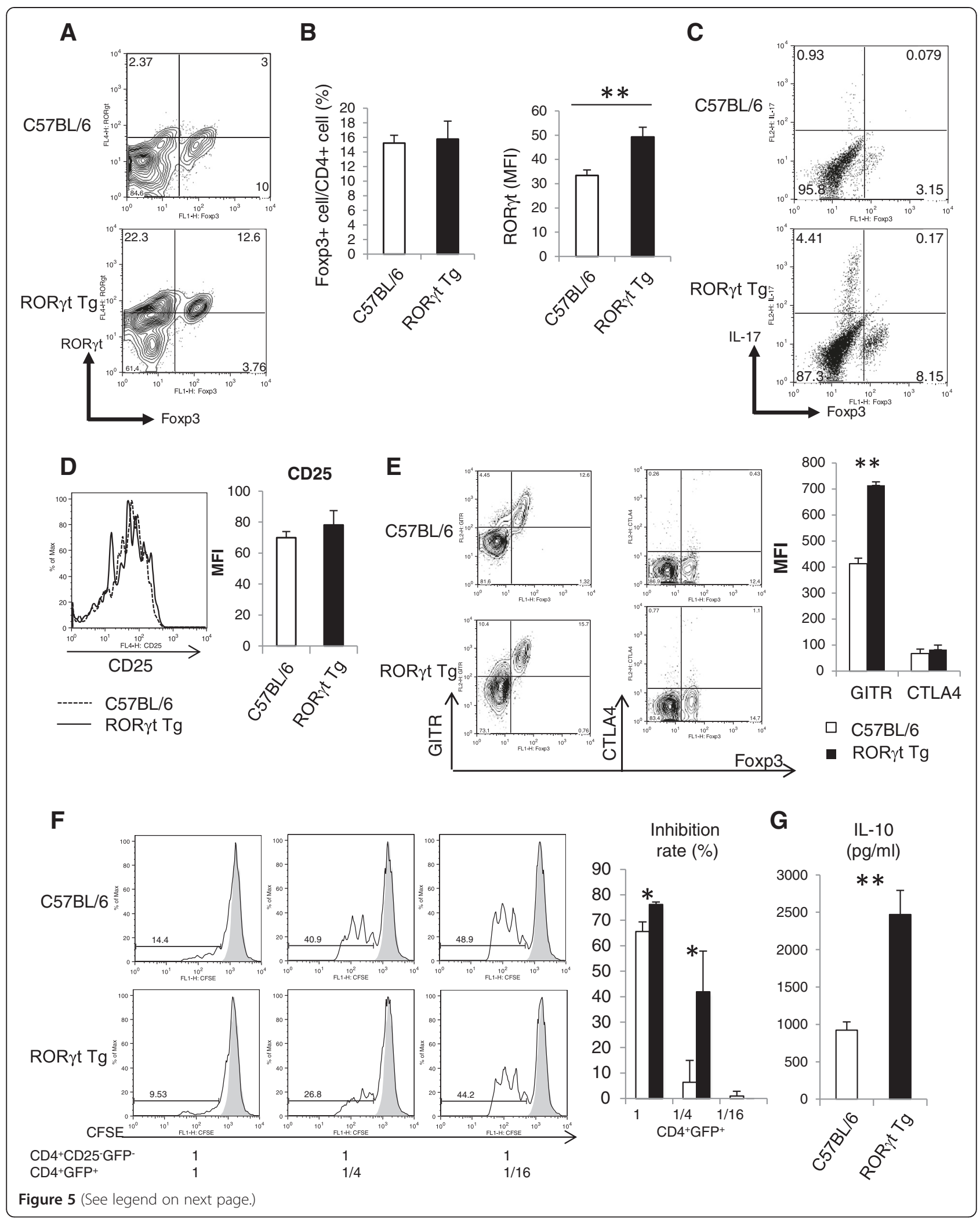




\section{(See figure on previous page.)}

Figure 5 Overexpression of RORyt augments the suppressive capacity of Foxp $3^{+}$CD4 ${ }^{+}$Treg cells. (A) At day 10 post first Cll immunization, the draining lymph-node (LN) cells were harvested from C57BL/6 mice ( $\mathrm{n}=3$ or 4 ) and RORyt Tg mice ( $\mathrm{n}=3$ or 4$)$ and subjected to flow cytometry. (B) Percentage of Foxp $3^{+}$cells among $\mathrm{CD} 4^{+}$T cells and mean fluorescence intensity (MFI) of RORyt in Foxp $3^{+}$CD4 ${ }^{+}$cells. (C) Cells were analyzed by staining for intracellular IL-17 and Foxp3. Data represent gated CD4 ${ }^{+}$. (D) Expression of CD25 on gated CD4 ${ }^{+}$Foxp3 ${ }^{+}$cells. (E) Expression of surface markers glucocorticoid-induced tumor necrosis factor receptor (GITR) and cytotoxic T-lymphocyte-associated protein 4 (CTLA4) on Foxp $3^{+} \mathrm{CD}^{+}$cells. Flow cytometric data (left) and MFI data of C57BL/6 mice and RORyt Tg mice. (F) Carboxyfluorescein diacetate succinimidyl ester (CFSE)-labeled CD4 ${ }^{+} \mathrm{CD} 25^{-} \mathrm{GFP}^{-}$cells from C57BL/6-Foxp3 ${ }^{\mathrm{GFP}}$ mice cultured with or without CD4 ${ }^{+} \mathrm{GFP}^{+}$cells from C57BL/6-Foxp3 ${ }^{\mathrm{GFP}}$ mice or RORyt Tg-Foxp3 ${ }^{\text {GFP }}$ mice and stimulated with anti-CD3/28 beads for $72 \mathrm{~h}$. Left, representative data of two independent experiments with three mice per group; right, percentage of inhibition rate. (G) IL-10 production by CD4 ${ }^{+} \mathrm{GFP}^{+}$cells of splenocytes stimulated for $72 \mathrm{~h}$ with anti-CD3/28 beads from C57BL/6-Foxp3 ${ }^{\text {GFP }}$ and RORyt Tg-Foxp3 ${ }^{\text {GFP }}$ mice. Representative data of two independent experiments with similar results, and are mean \pm standard error of the mean values. ${ }^{*} P<0.05$, ${ }^{* *} P<0.01$ versus C57BL/6 mice, Student's $t$-test.

\section{RORyt overexpression enhances the chemotactic activity of Foxp $3^{+}$Treg cells}

Because CCR6 expression is positively regulated by ROR $\gamma \mathrm{t}$ and contributes to the recruitment of cells to the inflamed joints [14], we analyzed CCR6 expression on CD4 ${ }^{+} \mathrm{T}$ cells after CII immunization. CCR6 expression on $\mathrm{CD}^{+}{ }^{+} \mathrm{T}$ cells was significantly higher in RORyt Tg than C57BL/6 mice (Figure 6A, $P<0.01$ ). Interestingly, the highest expression of CCR6 was observed in Foxp $3^{+} \mathrm{CD}^{+}$Treg cells in RORyt Tg mice compared with Foxp $3^{+} \mathrm{CD}^{+}$Treg cells in C57BL/6 mice and Foxp3 ${ }^{-}$non-Treg cells in RORyt Tg mice (Figure 6B).

To determine the chemotactic activity of $\mathrm{CD} 4^{+} \mathrm{T}$ cells to CCL20, the in vitro migration assay was performed using $\mathrm{CCR}^{+}$cells. More $\mathrm{CD}^{+}$cells migrated in response to CCL20 in RORyt Tg than C57BL/6 mice (Figure 6C). The migrating $\mathrm{CD}^{+} \mathrm{T}$ cells of RORyt $\mathrm{Tg}$ mice were enriched for Foxp $3^{+} \mathrm{T}$ cells (Figure 6D). In another in vivo experiment on mice, CIA was induced in both C57BL/6Foxp $3^{\mathrm{GFP}}$ and RORyt Tg-Foxp3 ${ }^{\mathrm{GFP}}$ reporter mice, and the expression levels of CCR6 and GFP in CD4 ${ }^{+} \mathrm{T}$ cells infiltrating the joints were analyzed by flow cytometry. Similar to the results of in vitro migration assay, more $\mathrm{CCR}^{+}$ $\mathrm{GFP}^{+}$Treg cells migrated into the joints of RORyt TgFoxp3 ${ }^{\text {GFP }}$ reporter mice than C57BL/6-Foxp3 ${ }^{\text {GFP }}$ reporter mice (Figure 6E). Considered together, these findings suggest that overexpression of RORyt induced CCR6 expression in Foxp ${ }^{+}$Treg cells and that the latter cells are enriched in the inflamed joints of RORyt Tg mice.

\section{Neutralization of IL-10 exacerbates CIA in RORyt Tg mice}

To clarify whether the suppression of CIA is related to IL-10, we administrated anti-IL-10 monoclonal antibody (mAb) to neutralize IL-10 in the course of CIA. The severity of arthritis was significantly exacerbated in both C57BL/6 mice and ROR $\gamma \mathrm{t} \mathrm{Tg}$ mice administrated with anti-IL-10 mAb compared with the mice with isotype control antibody, respectively (Figure 7A). However, suppression of CIA was not completely cancelled in RORyt $\mathrm{Tg}$ mice with the administration of anti-IL-10 mAb, although there was no statistically significant difference between C57BL/6 mice and RORyt Tg mice treated by
anti-IL-10 mAb (Figure 7A). We also examined the effect of IL-10 neutralization on the chemotactic activity of $\mathrm{CD}^{+} \mathrm{T}$ cells isolated from draining LNs at day 10 post first CII immunization in vitro. There was no significant difference in the migration of $\mathrm{CD} 4^{+} \mathrm{T}$ cells in response to CCL20 by the addition of anti-IL-10 mAb in both two groups of mice (Figure $7 \mathrm{~B}$ ). These data indicated that IL-10 is related to the inhibition of the development of CIA in ROR $\gamma \mathrm{t} \mathrm{Tg}$ mice.

\section{Discussion}

The transcription factor ROR $\gamma$ t is a master regulator of the differentiation of Th17 cells and expression of Th17 cytokines; IL-17A, IL-17 F, IL-22 and IL-21 [13]. Previous studies indicate that both IL-17 and Th17 cells seem to be involved in the pathogenesis of rheumatoid arthritis and animal model of autoimmune arthritis [3-7,17]. We have previously reported that the development of murine autoimmune arthritis is suppressed by the overexpression of T-bet, a master regulator of differentiation of Th1 cells, and suggested that Th17 cells differentiation is inhibited by T-bet through downregulation of ROR $\gamma t$ [16]. To elucidate the effects of ROR $\gamma t$ on $\mathrm{T}$ cell function in autoimmune arthritis, we used RORyt Tg mice under the control of CD2 promoter. In ROR $\gamma$ t Tg mice, most T cells were considered Th17 cells based on the high expression level of RORyt and production of high amounts of IL-17, compared to comparable levels of IFNy and IL-4 found in WT mice [16]. Contrary to our expectation, overexpression of RORyt provided protection against the development of autoimmune arthritis in mice. While the exact mechanism of this protection is unknown, we propose three scenarios: imbalance in Th1/Th17 cell ratio, low anti-CII antibody formation, and $\mathrm{CD}_{4}^{+}$Treg cell hyperfunction.

Does imbalance in the Th17/Th1 cell ratio play a pathogenic role in experimentally induced CIA in ROR $\gamma \mathrm{t} \mathrm{Tg}$ mice? Previous studies reported that Th1 cells have antiinflammatory properties in experimental arthritis $[16,23,24]$. Accordingly, we focused in this study on cytokine production and transcription factor expression in CII reactive $\mathrm{CD}^{+}{ }^{+} \mathrm{T}$ cells. The results showed significantly high IL-17 

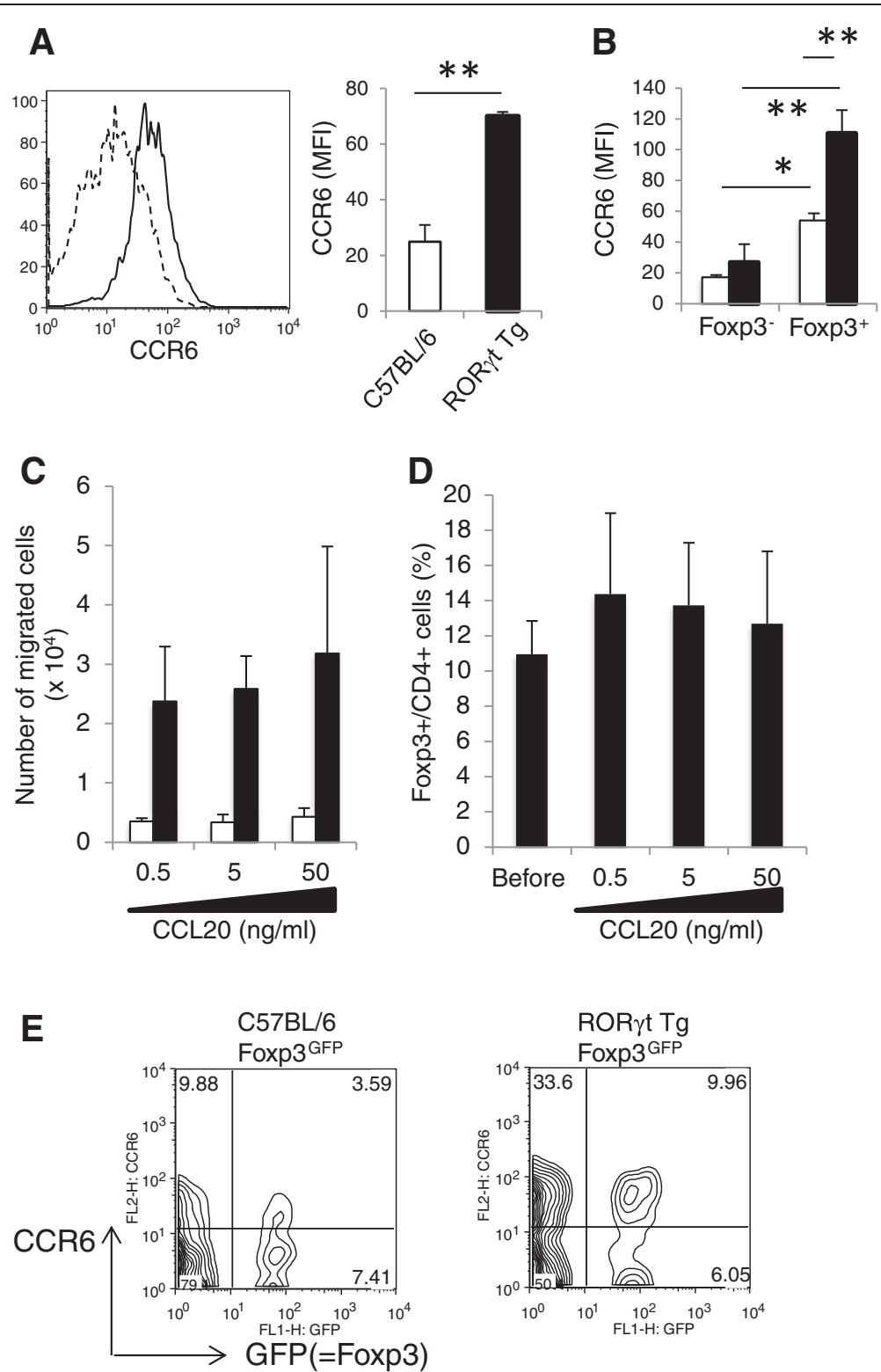

Figure 6 RORyt enhances chemotaxis of Foxp3 $3^{+}$Treg cells into inflamed tissues. (A) CCR6 expression in CD4 ${ }^{+}$T cells of C57BL/6 mice and RORyt Tg mice. (B) CCR6 expression in Foxp3 ${ }^{+} \mathrm{CD}^{+}$Treg cells and Foxp3 ${ }^{-} \mathrm{CD}^{+}$non-Treg cells from of C57BL/6 mice (open bars) and RORyt Tg mice (closed bars). (C) CD4 ${ }^{+}$cells were isolated by magnetic-activated cell sorting (MACS) from draining lymph-node (LN) cells of C57BL/6 mice (open bars) and RORyt Tg mice (closed bars), and added to the upper well of a Transwell system. The migration assay was performed in the presence of the indicated concentrations of CCL20 added to the bottom well. Data are numbers of respective cells that migrated to the bottom well counted by FACS. (D) CD4 $4^{+}$cells of RORyt Tg mice were subjected to intracellular Foxp3 staining, and then subjected to the migration analysis as in $\mathbf{C}$. (C, D) Data are mean \pm standard error of the mean. ${ }^{*} P<0.01$, versus C57BL/6 mice, Student's $t$-test. (E) Collagen-induced arthritis was induced in C57BL/6-Foxp3 ${ }^{\text {GFP }}$ and RORyt Tg-Foxp3 ${ }^{\text {GFP }}$ mice, and $\mathrm{CD}^{+} \mathrm{CD}^{+} \mathrm{T}$ cells that infiltrated the ankle joints were harvested at day 30 post first type II collagen (CII) immunization and analyzed for green fluorescent protein (GFP) and CCR6 expression. Representative data of two independent experiments with similar results. MFI, mean fluorescence intensity.

production and RORyt expression in CII-reactive T cells of RORYt Tg mice, but no differences in IFNy production and T-bet expression, compared with C57BL/6 mice. These findings argue against the Th17/Th1 cell imbalance theory as an explanation for the suppression of CIA in RORyt Tg mice.
Is anti-CII antibody titer important in the development of CIA in RORyt Tg mice? A previous study showed that the development of CIA correlates well with the level of serum anti-CII antibody, particularly the IgG2 subclass [20]. The significantly low level of serum anti-CII total IgG could be one of the causes for the 


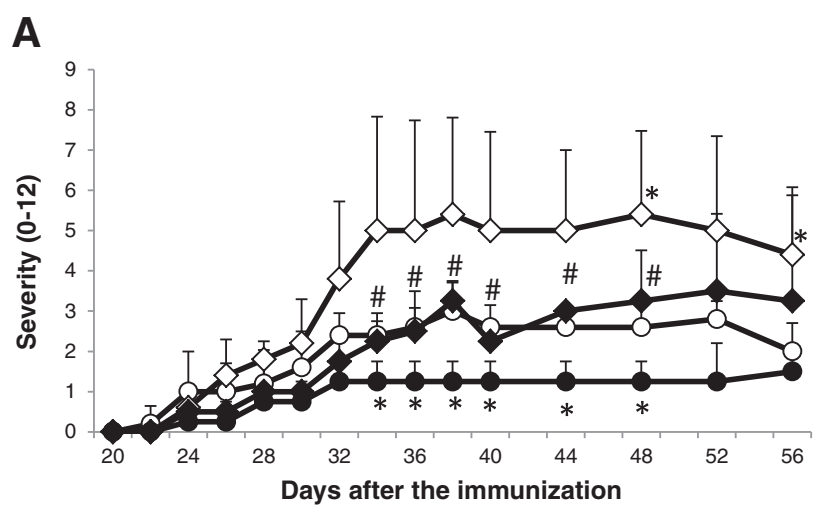

$-\mathrm{C} 57 \mathrm{BL} / 6$ isotype ctrl Ab
$-\mathrm{ROR} \gamma \mathrm{Tg}$ isotype ctrl Ab

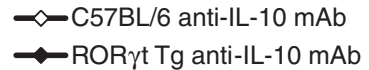

B

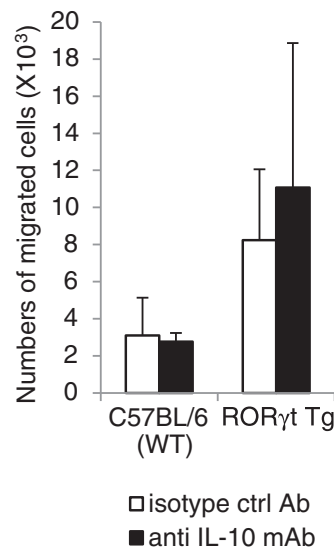

Figure 7 Neutralization of IL-10 exacerbates collagen-induced arthritis in RORyt Tg mice. (A) C57BL/6 mice ( $\mathrm{n}=5$ ) and RORyt Tg mice ( $\mathrm{n}=4$ ) were immunized intradermally with chicken type II collagen (CII) emulsified with complete Freund's adjuvant (CFA) on days 0 and 21 . Anti-IL-10 monoclonal antibody (mAb) or isotype control antibody (ctrl Ab) were administrated intraperitoneally every 2 days from day 22 to 30 post first Cll immunization. Severity of arthritis was shown. Representative data are mean \pm standard error of the mean (SEM) values. * $P<0.05$ versus C57BL/6 mice with the administration of isotype ctrl Ab, ${ }^{\#} P<0.05$ versus RORyt Tg mice with the administration of isotype ctrl Ab, Student's $t$-test. (B) At day 10 post first CII immunization, $\mathrm{CD}^{+}$cells were isolated by magnetic-activated cell sorting (MACS) from draining lymph-node cells of C57BL/6 mice (open bars) and RORyt Tg mice (closed bars), and added to the upper well of a Transwell system. The migration assay was performed in the presence of CCL20 and anti-IL-10 mAb or isotype ctrl Ab added to the bottom well. Data are number of respective cells that migrated to the bottom well counted by FACS. Representative data of two independent experiments with similar results and are mean \pm SEM value.

suppression of CIA in ROR $\gamma \mathrm{t} \mathrm{Tg}$ mice, although there was no significant difference in CII-specific IgG2 subclass between the two types of mice. Leavenworth et al. [25] reported recently that Tfh-dependent autoantibody production results in immune complex formation in joint tissues, and complement activation, and that enhanced intra-articular inflammatory responses induced by Th17 cells play a role in the development of autoimmune arthritis. Tfh cells are known to express CXCR5, ICOS, and PD-1 as superficial markers, and to produce IL-21 for help for B cells [26-28]. In addition, lineage commitment of Tfh cells is directly regulated by transcription factor Bcl-6 [28]. Our results showed lower expression levels of Bcl-6 and IL-21 in CXCR5 ${ }^{+} \mathrm{CD} 4{ }^{+}$Tfh cells in RORyt Tg mice than C57BL/6 mice, although the $\mathrm{ICOS}^{+} \mathrm{PD}-1^{+}$Tfh cells increased in draining LNs of RORyt Tg mice, suggesting that the differentiation and the function of Tfh cells might be suppressed in ROR $\gamma \mathrm{t}$ Tg mice, and which is associated with the reduced anti-CII antibody formation and the suppression of the development of CIA. Although the precise mechanism was not elucidated, the low level of anti-CII antibody might be also related to the diminished ectopic lymphoid follicle formation induced by local synovial inflammation, which is distinct feature of autoimmune arthritis $[29,30]$.

The third possible etiology of arthritis in RORyt Tg mice involves overexpression of ROR $\gamma \mathrm{t}$. This scenario is based on the attenuation of CIA in not only ROR $\gamma \mathrm{t}$ Tg mice but also in C57BL/6 mice with adoptive transfer of $\mathrm{CD}^{+}{ }^{+} \mathrm{T}$ cells from ROR $\gamma \mathrm{t} \mathrm{Tg}$ mice. Forkhead family transcription factor Foxp3 is characteristically expressed in a major subset of regulatory T cells [31]. Foxp $3^{+}$Treg cells can suppress the activation of Th17 cells and other effector $\mathrm{T}$ cell subsets as well as the development of certain autoimmune diseases, including CIA [32]. Interestingly, ROR $\gamma \mathrm{t}$ expression on Foxp $3^{+}$Tregs was significantly upregulated in RORyt Tg mice compared with C57BL/6 mice, although there were no difference between the two groups of mice in Foxp3 expression on $\mathrm{CD}^{+}{ }^{+} \mathrm{T}$ cells. Foxp $3^{+}$Treg cells also expressed high levels of the co-inhibitory molecule, GITR [33], produced high amounts of IL-10 but not IL-17, and suppressed the proliferation of effector $\mathrm{T}$ cells in RORyt Tg mice. Moreover, the suppression of CIA was partially cancelled by the neutralization of IL-10 in ROR $\gamma \mathrm{t}$ Tg mice, suggesting that IL-10 produced from Foxp $3^{+}$Treg cells might be related to attenuation of CIA in ROR $\gamma \mathrm{t} \mathrm{Tg}$ mice. In addition to our observations, Lochner et al. reported that ROR $\gamma \mathrm{t}^{+} \mathrm{T}$ cells include pro-inflammatory IL17-producing Th17 cells and IL-10-producing Foxp $3^{+}$Treg cells, and that equilibrium of two types of ROR $\gamma \mathrm{t}^{+}$cells are tightly controlled in vivo [34]. Although the precise mechanism of enhanced suppressive capacity of Foxp $3^{+}$Treg cells in RORyt Tg mice was not elucidated, these data support our hypotheses that IL-10-producing ROR $\gamma \mathrm{t}^{+}$Foxp $3^{+}$ Treg cells suppress the development of CIA.

Previous studies report that ROR $\gamma$ t can induce the expression of CCR6, which is also known to play a role in 
arthritogenic Th17 cell recruitment to inflamed joints [14]. Furthermore, CCR6-expressing Treg cells can reduce the Th17-mediated inflammatory response [35,36]. In the present study, RORyt upregulation induced overexpression of CCR6 in Foxp3 ${ }^{+}$Treg cells, which in turn resulted in preferential migration of Foxp $3^{+}$Treg cells in response to CCL20, a ligand of CCR6. Although we have no direct evidence for the involvement of Foxp $3^{+}$Treg in the pathogenesis of CIA, the results of previous studies and our findings suggest upregulation of RORyt enhances the expression of CCR6 on Foxp $3^{+}$Treg cells, resulting in preferential infiltration of Foxp $3^{+}$Treg cells into inflamed joints and suppression of autoimmune synovitis.

\section{Conclusion}

Our results suggest that the protective effects of RORyt overexpression against the development of CIA in mice were mediated through the anti-inflammatory effects of intra-articular IL-10-producing CCR6 ${ }^{+} \mathrm{ROR}_{\mathrm{H}} \mathrm{t}^{+} \mathrm{Foxp}^{+}{ }^{+}$Treg cells. The results also suggest that modulation of transcription factor expression on $\mathrm{CD}_{4}^{+} \mathrm{T}$ cells is a potentially useful therapeutic approach in RA.

\begin{abstract}
Abbreviations
BCl-6: B cell lymphoma 6; CCL20: CC chemokine ligand 20; CCR6: CC chemokine receptor 6; CDNA: complementary deoxyribonucleic acid; CFA: complete Freund's adjuvant; CFSE: carboxyfluorescein diacetate succinimidyl ester; CIA: collagen induced arthritis; Cll: type II collagen; CTLA-4: cytotoxic T-lymphocyte-associated protein 4; CXCR5: CXC chemokine receptor 5; ELISA: enzyme-linked immunosorbent assay; FACS: fluorescenceactivated cell sorting; FBS: fetal bovine serum; Foxp3: forkhead box P3; GATA-3: GATA binding protein-3; GFP: green fluorescent protein; GITR: glucocorticoid-induced tumor necrosis factor receptor; GPI: glucose-6phosphate isomerase; ICOS: inducible T-cell do-stimulator; IFNY: interferon $\gamma$; IL: interleukin; LN: lymph node; mAb: monoclonal antibody; MACS: magneticactivated cell sorting; MFI: mean fluorescence intensity; PBS: phosphatebuffered saline; PCR: polymerase chain reaction; PD-1: programmed cell death-1; PI: propidium iodide; RA: rheumatoid arthritis; RNA: ribonucleic acid; RORyt Tg: RORyt transgenic; RORyt: retinoid-related orphan receptor gamma t; RT: reverse transcriptase; SEM: standard error of the mean; T-bet: T-box transcription factor; Tfh: T follicular helper; TGF- $\beta$ : transforming growth factor- $\beta$; Th: T helper; Treg: regulatory T; WT: wild-type.
\end{abstract}

\section{Competing interests}

The authors declare that they have no competing interests.

\section{Authors' contributions}

YK carried out the experiments and statistical analysis, and drafted the manuscript. ZY, MT, MY, and SK assisted in carrying out the experiments and manuscript preparation. MI, SS and $\mathrm{HT}$ assisted in data interpretation and manuscript preparation. KY, ST, IM, and TS conceived of the study, participated in its design and coordination, and helped to draft the manuscripts. All authors read and approved the final manuscript.

\section{Acknowledgements}

We thank Dr FG Issa for the critical reading of the manuscript. This work was supported by the Research Program for Intractable Diseases, Health and Labor Sciences Research Grants from the Ministry of Health, Labor and Welfare, Japan, and Grants-in Aid for Scientific Research (Grant-in Aid for Young Scientists (B)) from the Ministry of Education, Culture, Sports, Science and Technology and Japan Society for the Promotion of Science.

\section{Author details}

'Department of Internal Medicine, Faculty of Medicine, University of Tuskuba, 1-1-1 Tennodai, Tsukuba City, Ibaraki 305-8575, Japan. ${ }^{2}$ Department of Anatomy and Embryology, Faculty of Medicine, University of Tsukuba, 1-1-1 Tennodai, Tsukuba City, Ibaraki 305-8575, Japan. ${ }^{3}$ International Institute for Integrative Sleep Medicine (WPI-IIIS), University of Tsukuba, 1-1-1 Tennodai, Tsukuba City, Ibaraki 305-8575, Japan. ${ }^{4}$ Life Science Center, Tsukuba Advanced Research Alliance (TARA), University of Tsukuba, 1-1-1 Tennodai, Tsukuba City, Ibaraki 305-8575, Japan. ${ }^{5}$ Laboratory Animal Resource Center (LARC), University of Tsukuba, 1-1-1 Tennodai, Tsukuba City, Ibaraki 305-8575, Japan.

Received: 6 October 2014 Accepted: 23 March 2015

Published online: 20 April 2015

\section{References}

1. Zhu J, Paul WE. Peripheral CD4+ T-cell differentiation regulated by networks of cytokines and transcription factors. Immunol Rev. 2010;238:247-62.

2. Iwanami K, Matsumoto I, Tanaka-Watanabe Y, Inoue A, Mihara M, Ohsugi Y, et al. Crucial role of the interleukin-6/interleukin-17 cytokine axis in the induction of arthritis by glucose-6-phosphate isomerase. Arthritis Rheum. 2008;58:754-63.

3. Nakae S, Nambu A, Sudo K, Iwakura Y. Suppression of immune induction of collagen-induced arthritis in IL-17-deficient mice. J Immunol. 2003;171:6173-7.

4. Lubberts E, Koenders MI, Oppers-Walgreen B, van den Bersselaar L, Coenen-de Roo CJ, Joosten LA, et al. Treatment with a neutralizing anti-murine interleukin-17 antibody after the onset of collagen-induced arthritis reduces joint inflammation, cartilage destruction, and bone erosion. Arthritis Rheum. 2004;50:650-9.

5. Koenders MI, Lubberts E, Oppers-Walgreen B, van den Bersselaar L, Helsen MM, Di Padova FE, et al. Blocking of inteleukin-17 during reactivation of experimental arthritis prevents joint inflammation and bone erosion by decreasing RANKL and interleukin-1. Am J Pathol. 2005;167:141-9.

6. Chabaud M, Durand JM, Buchs N, Fossiez F, Page G, Frappart L, et al. Human interleukin-17: A T cell-derived proinflammatory cytokine produced by the rheumatoid synovium. Arthritis Rheum. 1999;42:963-70.

7. Shen H, Goodall JC, Hill Gaston JS. Frequency and phenotype of peripheral blood Th17 cells in ankylosing spondylitis and rheumatoid arthritis. Arthritis Rheum. 2009;60:1647-56.

8. Hwang ES, Szabo SJ, Schwartzberg PL, Glimcher LH. T helper cell fate specified by kinase-mediated interaction of T-bet with GATA-3. Science. 2005;307:430-3.

9. Zhou L, Lopes JE, Chong MM, Ivanov II, Min R, Victora GD, et al. TGF- $\beta$ induced Foxp3 inhibits TH17 cell differentiation by antagonizing RORyt function. Nature. 2008:453:236-41.

10. Szabo SJ, Kim ST, Costa GL, Zhang X, Fathman CG, Glimcher LH. A novel transcription factor, T-bet, directs Th1 lineage commitment. Cell. 2000;100:655-69.

11. Zhang DH, Cohn L, Ray P, Bottomly K, Ray A. Transcription factor GATA-3 is differentially expressed in murine Th1 and Th2 cells and controls Th2-specific expression of the interleukin-5 gene. J Biol Chem. 1997;272:21597-603.

12. Ivanov II, McKenzie BS, Zhou L, Tadokoro CE, Lepelley A, Lafaille JJ, et al. The orphan nuclear receptor RORyt directs the differentiation program of proinflammatory IL-17+ T helper cells. Cell. 2006;126:1121-33.

13. Miossec P, Kolls JK. Targeting IL-17 and TH17 cells in chronic inflammation. Nature Rev Drug Discov. 2012;11:763-76.

14. Hirota K, Yoshitomi H, Hashimoto M, Maeda S, Teradaira S, Sugimoto N, et al. Preferential recruitment of CCR6-expressing Th17 cells to inflamed joints via CCL20 in rheumatoid arthritis and its animal model. J Exp Med. 2007;204:2803-12.

15. van Hamburg JP, Mus AM, de Bruijn MJ, de Vogel L, Boon L, Comelissen F, et al. GATA-3 protects against severe joint inflammation and bone erosion and reduces differentiation of Th17 cells during experimental arthritis. Arthritis Rheum. 2009;60:750-9.

16. Kondo Y, lizuka M, Wakamatsu E, Yao Z, Tahara M, Tsuboi H, et al. Overexpression of T-bet gene regulates murine autoimmune arthritis. Arthritis Rheum. 2012;64:162-72.

17. Leipe J, Grunke M, Dechant C, Reindl C, Kerzendorf U, Schulze-Koops H, et al. Role of Th17 cells in human autoimmune arthritis. Arthritis Rheum. 2010;62:2876-85

18. Yoh K, Morito N, Ojima M, Shibuya K, Yamashita Y, Morishima Y, et al. Overexpression of RORyt under control of the CD2 promoter induces 
polyclonal plasmacytosis and autoantibody production in transgenic mice. Eur J Immunol. 2012;42:1-11.

19. Buttgereit F, Zhou H, Kalak R, Gaber T, Spies CM, Huscher D, et al. Transgenic disruption of glucocorticoid signaling in mature osteoblasts and osteocytes attenuates $\mathrm{K} / \mathrm{BxN}$ mouse serum-induced arthritis in vivo. Arthritis Rheum. 2009;60:1998-2007.

20. Cho YG, Cho ML, Min SY, Kim HY. Type II collagen autoimmunity in a mouse model of human rheumatoid arthritis. Autoimmun Rev. 2007;7:65-70.

21. Ramsdell F. Foxp3 and natural regulatory T cells: key to a cell lineage? Immunity. 2003;19:165-8.

22. Fontenot JD, Rasmussen JP, Gavin MA, Rudensky AY. A function for interleukin 2 in Foxp3-expressing regulatory T cells. Nat Immunol. 2005:6:1142-51.

23. Chu CQ, Swart D, Alcorn D, Tocker J, Elkon KB. Interferon-y regulates susceptibility to collagen-induced arthritis through suppression of interleukin-17. Arthritis Rheum. 2007;56:1145-51.

24. Geboes L, De Klerck B, Van Balen M, Kelchtermans H, Mitera T, Boon L, et al. Freund's complete adjuvant induces arthritis in mice lacking a functional interferon- $\gamma$ receptor by triggering tumor necrosis factor a-driven osteoclastogenesis. Arthritis Rheum. 2007;56:2595-607.

25. Leavenworth JW, Wang X, Wenander CS, Spee P, Cantor H. Mobilization of natural killer cells inhibits development of collagen-induced arthritis. Proc Natl Acad Sci. 2011;108:14584-9.

26. Glatman Zaretsky A, Taylor JJ, King IL, Marshall FA, Mohrs M, Pearce EJ. T follicular helper cells differentiate from Th2 cells in response to helminth antigens. J Exp Med. 2009;206:991-9.

27. Chtanova T, Tangye SG, Newton R, Frank N, Hodge MR, Rolph MS, et al. T follicular helper cells express a distinctive transcriptional profile, reflecting their role as non-Th1/Th2 effector cells that provide help for B cells. J Immunol. 2004;173:68-78.

28. Yu D, Rao S, Tsai LM, Lee SK, He Y, Sutcliffe EL, et al. The transcriptional repressor $\mathrm{BCl}-6$ directs $\mathrm{T}$ follicular helper cell lineage commitment. Immunity. 2009;31:457-68.

29. Takemura S, Braun A, Crowson C, Kurtin PJ, Cofield RH, O'Fallon WM, et al. Lymphoid neogenesis in rheumatoid synovitis. J Immunol. 2001;167:1072-80.

30. Firestein GS. Evolving concepts of rheumatoid arthritis. Nature. 2003;423:356-61

31. Hori S, Nomura T, Sakaguchi S. Control of regulatory T cell development by the transcription factor Foxp3. Science. 2003:299:1057-61.

32. Ko HJ, Cho ML, Lee SY, Oh HJ, Heo YJ, Moon YM, et al. CTLA4-Ig modifies dendritic cells from mice with collagen-induced arthritis to increase the CD4 + CD25 + Foxp3+ regulatory T cell population. J Autoimmun. 2010;34:111-20.

33. Uraushihara K, Kanai T, Ko K, Totsuka T, Makita S, liyama R, et al. Regulation of murine inflammatory bowel disease by CD25+ and CD25-CD4+ glucocorticoid-induced TNF receptor family-related gene + regulatory $T$ cells. J Immunol. 2003;171:708-16.

34. Lochner M, Peduto L, Cherrier M, Sawa S, Langa F, Varona R, et al. In vivo equilibrium of proinflammatory $\mathrm{IL}-17+$ and regulatory $\mathrm{IL}-10+$ Foxp3+ RORyt + T cells. J Exp Med. 2008;205:1381-93.

35. Yamazaki T, Yang XO, Chung Y, Fukunaga A, Nurieva R, Pappu B, et al. CCR6 regulates the migration of inflammatory and regulatory cells. J Immunol. 2008;181:8391-401.

36. Villares R, Cadenas V, Lozano M, Almonacid L, Zaballos A, Martinez-A C, et al. CCR6 regulates EAE pathogenesis by controlling regulatory CD4+ T-cell recruitment to target tissues. Eur J Immunol. 2009;39:1671-81.

\section{Submit your next manuscript to BioMed Central and take full advantage of:}

- Convenient online submission

- Thorough peer review

- No space constraints or color figure charges

- Immediate publication on acceptance

- Inclusion in PubMed, CAS, Scopus and Google Scholar

- Research which is freely available for redistribution 